\title{
Aa. Vv., Qui fait la France?, Chroniques d'une société annoncée
}

Ilaria Vitali

\section{(e) OpenEdition}

1 Journals

\section{Edizione digitale}

URL: http://journals.openedition.org/studifrancesi/9051

DOI: 10.4000/studifrancesi.9051

ISSN: 2421-5856

\section{Editore}

Rosenberg \& Sellier

\section{Edizione cartacea}

Data di pubblicazione: 1 octobre 2008

Paginazione: 496

ISSN: 0039-2944

\section{Notizia bibliografica digitale}

Ilaria Vitali, «Aa. Vv., Qui fait la France?, Chroniques d'une société annoncée», Studi Francesi [Online], 155

(LII | II) | 2008, online dal 30 novembre 2015, consultato il 12 janvier 2021. URL: http://

journals.openedition.org/studifrancesi/9051 ; DOI: https://doi.org/10.4000/studifrancesi.9051

Questo documento è stato generato automaticamente il 12 janvier 2021.

\section{(c) (i) $\ominus$}

Studi Francesi è distribuita con Licenza Creative Commons Attribuzione - Non commerciale - Non opere derivate 4.0 Internazionale. 


\title{
Aa. Vv., Qui fait la France?, Chroniques d'une société annoncée
}

\author{
Ilaria Vitali
}

\section{NOTIZIA}

Qui fait la France?, Chroniques d'une société annoncée, Paris, Stock, 2007, pp. 269.

1 Questa raccolta dal provocatorio titolo Chroniques d'une société annoncée è il primo volume di «Qui fait la France?», un collettivo fondato da dieci scrittori della banlieue parigina, i cosiddetti «immigrati di seconda (o terza) generazione». Un collettivo giovane - creato nel 2007 da autori tra i venti e i trentacinque anni - ma con le idee chiare, messe nero su bianco in un vero e proprio manifesto, inserito in apertura di questo volume. «Parce que nous pensons que la France est un pays moderne dont le vivre-ensemble s'élabore par le décloisonnement des mentalités, la reconnaissance des souffrances particulières, la mise en récit de sa diversité et de ses imaginaires» (p. 7). È l'incipit del manifesto che racchiude il credo del gruppo.

2 La scelta di dare al collettivo un nome sotto forma di domanda, «Qui fait la France?», vuole portare l'attenzione su pesanti interrogativi, che mai come oggi, dopo le violenze dello scorso novembre a Villiers-le-Bel, nella periferia nord di Parigi, riaccendono il dibattito sulla situazione critica della banlieue e sui problemi d'integrazione dei suoi abitanti. Con un riuscito gioco di parole, il nome del collettivo può anche essere letto "Kiffer la France?", che nel gergo della banlieue significa “Amare la Francia?”. Un gioco linguistico che solleva nuove domande e la dice lunga sul credo letterario del gruppo, che fa della creatività stilistica e lessicale l'arma affilata per demolire qualche pregiudizio razziale.

3 È un sogno balzachiano quello degli autori, che vogliono raccontare con realismo la Francia in cui vivono in tutta la sua diversità culturale e linguistica. Le dodici novelle racchiuse in questo volume raccontano un paese che è difficile trovare nei romanzi contemporanei dei cosiddetti «français de souche», e che tuttavia rispecchia da vicino 
quello reale. Tra i racconti segnaliamo quello di Mabrouck RACHEDI, già autore di un bellissimo romanzo sulla banlieue parigina dal titolo Le poids d'une âme (2006), che si mette qui nei panni di un livreur de pizza vittima di una strana patologia: non riesce a sopportare la bruttezza dei sette grattacieli che lo circondano e tenta di fare dei pericolosi détours - come recita il titolo della novella - per evitare di vederli. Naturalmente, questa pratica lo porterà a consegnare le pizze in ritardo e ad essere licenziato, nonché rinchiuso in un ospedale psichiatrico (situato anch'esso, beffardamente, all'interno di un grattacielo). Il racconto, come altri in questo volume, porta l'attenzione sulla laideur architecturale delle banlieue parigine, costruite come cités ouvrières tra gli anni Cinquanta e Sessanta. A partire dagli anni Settanta, il ministro dell'équipement et $d u$ logement, Olivier Guichard, vieterà la costruzione di nuovi grattacieli: le cosiddette "tours de logement» sono accusate di aver prodotto un ambiente invivibile. Segnaliamo poi il racconto di Habiba MAHANY, che porta l'attenzione sul razzismo di cui sono ancora vittime questi francesi «d'origines difficiles». Nel suo Racisme aveugle un ragazzo nero in cerca di lavoro svolge un colloquio perfetto con il capo del personale di una grossa azienda, che decide di assumerlo. Tuttavia, l'uomo è cieco e non si è accorto del colore della pelle del ragazzo (che risponde ironicamente al nome di Baptiste Leblanc). Una volta informato che il ragazzo è nero, il capo del personale dimenticherà il colloquio perfetto e deciderà di non assumerlo. Un altro interessante racconto è quello di Faïza GuènE, regista di cortometraggi e autrice del best-seller Kiffe Kiffe demain, che racconta, con crudele ironia, gli sdoppiamenti di personalità di un carcerato schizofrenico.

4 Un volume che porta l'attenzione su temi di scottante attualità e risponde al desiderio di creare una letteratura "engagée, combattante et féroce» (p.8), che non lascerà indifferente il lettore.

5 Con un occhio rivolto al futuro, «Qui fait la France?» punta ad arricchire le sue file di nuovi talenti: è stato bandito un concorso di novelle il cui vincitore sarà inserito nella prossima raccolta del gruppo, in uscita a giugno 2008. 